\title{
Article \\ Coupling Effect of Salt Freeze-Thaw Cycles and Carbonation on the Mechanical Performance of Quick Hardening Sulphoaluminate Cement-Based Reactive Powder Concrete with Basalt Fibers
}

\author{
Guoping Huang ${ }^{1}$, Hui Wang ${ }^{2, *}$ and Feiting Shi ${ }^{3}$ (D) \\ 1 College of Civil Engineering, Hunan City University, Yiyang 413000, China; gphuang@hnu.edu.cn \\ 2 School of Civil and Environmental Engineering, Ningbo University, Ningbo 315000, China \\ 3 Engineering Department, Yancheng Institute of Technology, Yancheng 224051, China; shifeiting@ycit.cn \\ * Correspondence: huiwang123@aliyun.com
}

check for

updates

Citation: Huang, G.; Wang, H.; Shi, F. Coupling Effect of Salt Freeze-Thaw

Cycles and Carbonation on the

Mechanical Performance of Quick

Hardening Sulphoaluminate

Cement-Based Reactive Powder

Concrete with Basalt Fibers. Coatings

2021, 11, 1142. https://doi.org/

10.3390/coatings11091142

Academic Editor: Cecilia Monticelli

Received: 20 August 2021

Accepted: 14 September 2021

Published: 20 September 2021

Publisher's Note: MDPI stays neutral with regard to jurisdictional claims in published maps and institutional affiliations.

Copyright: (c) 2021 by the authors. Licensee MDPI, Basel, Switzerland. This article is an open access article distributed under the terms and conditions of the Creative Commons Attribution (CC BY) license (https:// creativecommons.org/licenses/by/ $4.0 /)$.

\begin{abstract}
The effect of salt freeze-thaw cycles coupled with carbonation on the mechanical performance of quick hardening sulphoaluminate cement-based reactive powder concrete combined with basalt fibers was investigated. The ratios of basalt fibers in sulphoaluminate cement-based reactive powder concrete (SAC-RPC) were $1 \%, 2 \%, 3 \%$ and $4 \%$ by the volume of concrete. The mechanical strengths (compressive strength, flexural strength and bonding strength) of SAC-RPC were investigated after curing for $5 \mathrm{~h}, 1 \mathrm{~d}, 14 \mathrm{~d}$ and $28 \mathrm{~d}$, respectively. Meanwhile, the mechanical strengths of resultant concrete were detected, when different $\mathrm{NaCl}$ freeze-thaw cycles and carbonation were adopted. Results showed that the addition of basalt fibers could effectively improve the mechanical strengths, especially the flexural strength of SAC-RPC. The dosage of 3.0\% was the threshold value affected mechanical strengths. The flexural, compressive and bonding strengths of SAC-RPC were higher than $8.53 \mathrm{MPa}, 34 \mathrm{MPa}$ and $3.21 \mathrm{MPa}$, respectively. The mass loss and mechanical strengths loss of SAC-RPC increased in the form of quadratic function with the increasing number of $\mathrm{NaCl}$ freeze-thaw cycles and varied in the form of quadratic decreasing function. Meanwhile, the effect of carbonation on the mechanical strengths of SAC-RPC can be ignored. Additionally, the coupling effect of salt freeze-thaw cycles and carbonation could accelerate the attenuation of concrete strength. The mechanical strengths loss demonstrated a decreased quadratic function with the increasing volume of basalt fibers.
\end{abstract}

Keywords: salt freeze-thaw cycles; carbonation; quick hardening; sulphoaluminate cement-based; basalt fibers

\section{Introduction}

Bridge is the pivotal part of building structures, which carries a lot of traffic load. However, damage often occurs to its deck due to the action of load on the surface. Meanwhile, the corrosive environmental action can accelerate the damage of the deck when in service. Therefore, the deck should be repaired timely.

So far, a variety of repair materials have been developed for the maintenance-repairing of the deck of bridges. The repairing materials can be divided into two categories, asphalt based repairing materials and cement-based repairing materials. Some research reports pointed out that the asphalt based repairing materials are convenient for construction and is followed by the fast open to traffic [1-3]. However, the resistance to aging on fatigue performance of the asphalt based repairing materials is poor. Moreover, the cost of asphalt based repairing materials is very high. Wang et al. [4-6] studied the effect of aging on fatigue performance of cement emulsified asphalt repairing material and found that the addition of cement could improve the fatigue life. Furthermore, the cement-based materials are often used in the repairing engineering of bridge deck [7-9]. Jin et al. [10-12], 
pointed out that the magnesium phosphate cement-based materials possessed impressive compressive and bending strengths higher than $13 \mathrm{MPa}$ and $3.5 \mathrm{MPa}$, respectively, after curing for $1 \mathrm{~h}$. Additionally, the tensile bonding strength of bricks repaired by asphalt based repairing materials after curing for $1 \mathrm{~d}$ was $2.466 \mathrm{MPa}$ [10]. Sulphoaluminate cement is a kind of quick hardening cement which has been used for repairing the roads and bridges for several years $[13,14]$. As found out in Hu's paper [15], sulphoaluminate cement mortar reinforced with micro-fine steel fibers displayed a maximum compressive strength of $19 \mathrm{MPa}$ and flexural strength of 5.3 MPa after cured for $3 \mathrm{~h}$. Prior researches [16-18] pointed out that the mechanical strength of Portland cement based materials at initial curing age ( $3 \mathrm{~h} \sim 3 \mathrm{~d}$ ) was much lower than that of sulphoaluminate cement based materials, while at a long curing age, the mechanical strength of Portland cement based materials showed higher strength than sulphoaluminate cement based materials [19]. The reactive powder concrete is a kind of concrete with high compactness, which shows excellent mechanical strengths and durability [20-23]. Hong et al. [24-26] manufactured the rapid hardening reactive powder concrete with steel fibers and investigated its following mechanical properties and durability.

The mechanical properties and durability of cement-based repairing materials have been reported in several studies. The bonding strength of the cement-based repairing material is a key factor for repairing the construction buildings, however, little attention has been paid to this aspect [27-30]. As reported in some research, the addition of steel fibers can improve the mechanical performance of cement concrete effectively. Nevertheless, the steel fibers are prone to corrosion, leading eventually to the reduction of durability. Basalt fiber has become a research and application hotspot in the international civil engineering field due to its excellent high temperature resistance, strong anti-seepage, anti-crack effect, green and environmental protection production process, low price and thermal expansion coefficient similar to that of cement. Yet, little attention has been drawn to the sulphoaluminate cement-based materials reinforced with basalt fibers. Meanwhile, few researchers have paid attention to the durability of basalt fibers reinforced sulphoaluminate cement-based materials.

This paper was aimed to investigate the influence of curing age and the coupling effect of salt freeze-thaw cycles and carbonation on the mechanical performances of basalt fibers reinforced quick hardening sulphoaluminate cement-based reactive powder concrete (SAC-RPC), which will provide a new kind of rapid repairing for the concrete construction buildings.

\section{Experimental}

2.1. Raw Materials

Type XK-DQXWY chopped basalt fibers with the length of $3 \mathrm{~cm}$ and the diameter of 5.5-6.5 $\mu \mathrm{m}$ produced by Shanghai Chenqi COBIT Co., Ltd., Shanghai, China, were used in this study. The density of basalt fibers used in this research was $2.635 \mathrm{~g} / \mathrm{cm}^{3}$. Additionally, the average elastic modulus and the tensile strength of these fibers were $10,520 \mathrm{MPa}$ and $4325 \mathrm{MPa}$, respectively. The dosages of basalt fibers applied in this study were 1\%, 2\%, $3 \%$ and $4 \%$ by the volume of sulphoaluminate cement-based reactive powder concrete (SAC-RPC). Binder materials used in this study were rapid hardening sulphoaluminate cement (R.SAC) produced by Tangshan Polar Bear Building Materials Co., Ltd., Tangshan, China, with a strength grade of $42.5 \mathrm{MPa}$, Silica fume (SF) possessing a specific surface area of $15 \mathrm{~m}^{2} / \mathrm{g}$ and more than $98 \% \mathrm{SiO}_{2}$, and granulated blast furnace slag powder (GGBS) with density, specific surface area and loss on ignition of $2.9 \mathrm{~g} / \mathrm{cm}^{3}, 436 \mathrm{~m}^{2} / \mathrm{g}$ and $2.3 \%$, respectively. The quartz sand with particle sizes of $1-0.71 \mathrm{~mm}, 0.59-0.35 \mathrm{~mm}$ and $0.15-$ $0.297 \mathrm{~mm}$ was used as aggregate in this study. The mass ratios of quartz sand with particle sizes of $1-0.71 \mathrm{~mm}, 0.59-0.35 \mathrm{~mm}$ and $0.15-0.297 \mathrm{~mm}$ were 1:1.5:0.8. The quartz sand possessed $99.6 \% \mathrm{SiO}_{2}, 0.02 \% \mathrm{Fe}_{2} \mathrm{O}_{3}$ and other ingredients. In this study, the binder sand ratio was 1.25, and the mass ratios of cement: SF: GGBS were 1:0.5:0.15. In order to make sure enough fluidity of fresh basalt fibers reinforced SAC-RPC, the polycarboxylate-based 
water-reducing agent with the water-reducing rate of $40 \%$ provided by Shenteng Co., Ltd., Lingshou, China was applied. $\mathrm{Li}_{2} \mathrm{SO}_{4}$, tartaric acid, polyether defoamer produced by Yingshan, Co., Ltd., Shanghai, China were used as early strength agent, retarder and defoamer in this study. Furthermore, for all specimens, the lithium sulfate, defoamer and tartaric acid in this study are $0.15 \%, 0.2 \%$ and $0.6 \%$ by mass of cementitious materials, respectively. Tables 1 and 2 show the particle size distribution and chemical composition of cementitious materials.

Table 1. Particle size distribution of the raw materials/\%.

\begin{tabular}{cccccccc}
\hline \multirow{2}{*}{ Types } & \multicolumn{7}{c}{ Particle Size/ $\mathbf{\mu m}$} \\
\cline { 2 - 8 } & $\mathbf{0 . 3}$ & $\mathbf{0 . 6}$ & $\mathbf{1}$ & $\mathbf{4}$ & $\mathbf{8}$ & $\mathbf{6 4}$ & $\mathbf{3 6 0}$ \\
\hline Cement & 0 & 0.33 & 2.66 & 15.01 & 28.77 & 93.59 & 100 \\
Slag Power & 0.025 & 0.1 & 3.51 & 19.63 & 35.01 & 97.9 & 100 \\
Silica Fume & 31.2 & 58.3 & 82.3 & 100 & 100 & 100 & 100 \\
\hline
\end{tabular}

Table 2. Chemical composition of the cementitious materials.

\begin{tabular}{cccccccc}
\hline Types & $\mathrm{SiO}_{\mathbf{2}}$ & $\mathrm{Al}_{\mathbf{2}} \mathbf{O}_{\mathbf{3}}$ & $\mathrm{Fe}_{\mathbf{2}} \mathrm{O}_{3}$ & $\mathbf{M g O}$ & $\mathrm{CaO}$ & $\mathbf{S O}_{3}$ & $\mathrm{TiO}_{\mathbf{2}}$ \\
\hline Cement & 13.95 & 22.46 & 2.67 & 2.92 & 39.39 & 14.34 & 1.66 \\
Slag Power & 34.06 & 14.74 & 0.23 & 9.73 & 35.93 & 0.23 & 3.51 \\
Silica Fume & 90 & 0.2 & 0.6 & 0.2 & 0.4 & 0 & 7.4 \\
\hline
\end{tabular}

\subsection{Specimen Preparation and Measurement Methods}

The SAC-RPC can be manufactured following these steps:

The powder admixtures (sulphoaluminate cement, silica fume, slag powder, quartz sand, lithium sulfate, defoamer and tartaric acid) are firstly mixed in the UJZ-15 mortar mixer Hebei Daoneng Construction Engineering Co., Ltd., Cangzhou, China, for $0.5 \mathrm{~min}$. Then, the basalt fibers were added and mixed for another $2 \mathrm{~min}$. After this mixing, the water-reducing agent is mixed with water and stirred in the mixture for the last $5.5 \mathrm{~min}$. The slump flow of fresh RPC paste is adjusted to $210-230 \mathrm{~mm}$ by water-reducing agent. DF-04 polyether surfactant with density of $0.4 \mathrm{~g} / \mathrm{cm}^{3}$ and $\mathrm{pH}$ of $7.0-7.5$ produced by Yingshan New Material Technology Co., Ltd. is used to eliminate air bubbles in RPC. After mixing, the fresh SAC-RPC was poured into the molds to manufacture the specimens. The specimens with sizes of $40 \mathrm{~mm} \times 40 \mathrm{~mm} \times 160 \mathrm{~mm}, 100 \mathrm{~mm} \times 100 \mathrm{~mm} \times 400 \mathrm{~mm}$ and $100 \mathrm{~mm} \times 100 \mathrm{~mm} \times 100 \mathrm{~mm}$ were applied to the experiments of mechanical strengths, $\mathrm{NaCl}$ freeze-thaw cycles and the carbonation, respectively. All specimens were cured in the room environment $\left(20 \pm 2{ }^{\circ} \mathrm{C}\right.$ and relative humidity of $\left.40 \pm 2 \%\right)$ for $1 \mathrm{~h}$ before demolding. After demolding, all specimens were cured in the standard curing room (temperature of $20 \pm 2{ }^{\circ} \mathrm{C}$ and relative humidity of above $95 \%$ ) for different curing ages. Figure 1 shows the manufacturing process of the specimens.

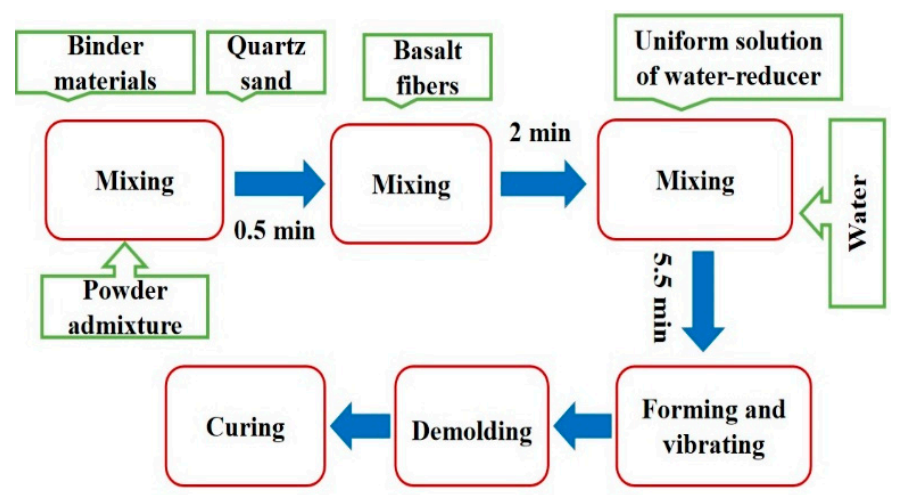

Figure 1. The manufacturing process of the specimens. 
The mechanical strengths (compressive strength and flexural strength) of specimens were determined by the YAW-300 microcomputer full-automatic universal tester with the maximum testing force of $300 \mathrm{kN}$ provided by Henruijin Co., Ltd., Jinan, China according to GB/T 17671-1999 Chinese standard [31]. Additionally, the experimental process of the bonding strength is described as following. The cement mortars made by ordinary Portland cement and quartz sand were prepared for the measurement of bonding strength. The water-cement ratio of the cement mortar was 0.2 , and the sand-cement ratio was 2.5. After the specimens were demolding and cured in standard curing room for 28 days, the specimens were cut in two halves and each half of specimens was repaired by the SAC-RPC. The specimen for the measurement of bonding strength is shown in Figure 2.

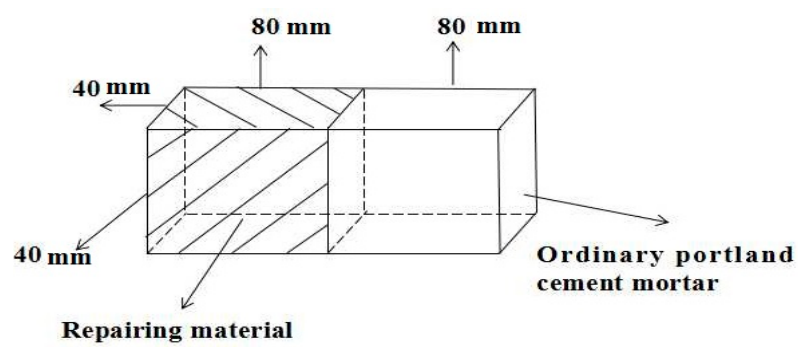

Figure 2. Specimen for the measurement of bonding strength.

The experiments of $\mathrm{NaCl}$ freeze-thaw cycles and carbonation test were carried out according to the Chinese Standard GB/T 50082-2009 [32]. All specimens for the experiment of $\mathrm{NaCl}$ freeze-thaw cycles were cured in the standard curing room for 24 days. The BWDR-I rapid freeze-thaw concrete testing machine produced by Cangzhou Zerui Test Instrument Co., Ltd., Cangzhou, China was provided for the experiment of $\mathrm{NaCl}$ freezethaw cycles. The temperature for $\mathrm{NaCl}$ freeze-cycles was $-15-8{ }^{\circ} \mathrm{C}$. Before experiment of $\mathrm{NaCl}$ freeze-cycles, all specimens were immersed in $3 \% \mathrm{NaCl}$ solution for 4 days. After this process, the specimens were moved in the stainless-steel sealed casing filled with $3 \% \mathrm{NaCl}$ solution for the experiments of $\mathrm{NaCl}$ freeze-cycles. The specimens cured for 28 days were applied for the experiment of carbonation. CCB-70F automatic concrete carbonation test box produced by Tianjin Deste Instrument Technology Co., Ltd. (Tianjin, China) was used for the carbonation experiment. The concentration of carbon dioxide for the carbonation experiment was $20 \%$ by the mass ratio of the total mass of gas. The specimens for the carbonation experiment were cured in the CCB-70F automatic concrete carbonation test box for 60 days before determination. The coupling effects of $\mathrm{NaCl}$ freeze-thaw cycles and carbonation can be described as the following steps. Three specimens of each group were cured in the CCB-70F automatic concrete carbonation test box for 60 days and then the specimens were moved for the experiment of $\mathrm{NaCl}$ freeze-thaw cycles.

\section{Results and Discussion}

\subsection{Mechanical Strength}

Figure 3 shows the flexural and compressive strengths of basalt fibers reinforced SAC-RPC. As shown in Figure 3, the flexural and compressive strengths of basalt fibers reinforced SAC-RPC increased with the increasing dosage of basalt fibers and the curing time. When the curing age was $5 \mathrm{~h}$, the flexural and compressive strengths of basalt fibers reinforced SAC-RPC was higher than $8.53 \mathrm{MPa}$ and $34 \mathrm{MPa}$, respectively, which was enough to the passage of vehicles. When the dosages of basalt fibers increased from $0 \%$ to $1 \%$, the flexural and compressive strengths of basalt fibers reinforced SAC-RPC increased slowly, due to the fact that the basalt fibers could effectively decrease crack propagation and improve the mechanical strengths of SAC-RPC $[33,34]$. However, the agglomeration of basalt fibers could induce the reduction in the mechanical strengths [35]. When the content of basalt fibers was $0-1 \%$, the enhancement effect of basalt fibers is close to the weakening effect. Therefore, the mechanical strengths of basalt fibers reinforced SAC-RPC varied slowly with the increasing addition of basalt fibers. Meanwhile, when the content of 
basalt fibers increased from $1 \%$ to $3 \%$, the mechanical strengths of basalt fibers reinforced SAC-RPC increased obviously. This was attributed to the reinforcement of basalt fibers [36]. Additionally, when the dosages of basalt fibers increased from $3 \%$ to $4 \%$, the mechanical strengths of basalt fibers reinforced SAC-RPC reached a stable value. Consequently, it could be obtained from Figure 3, the basalt fibers volume of 3\% was the threshold value of mechanical strengths of basalt fibers reinforced SAC-RPC in this study.

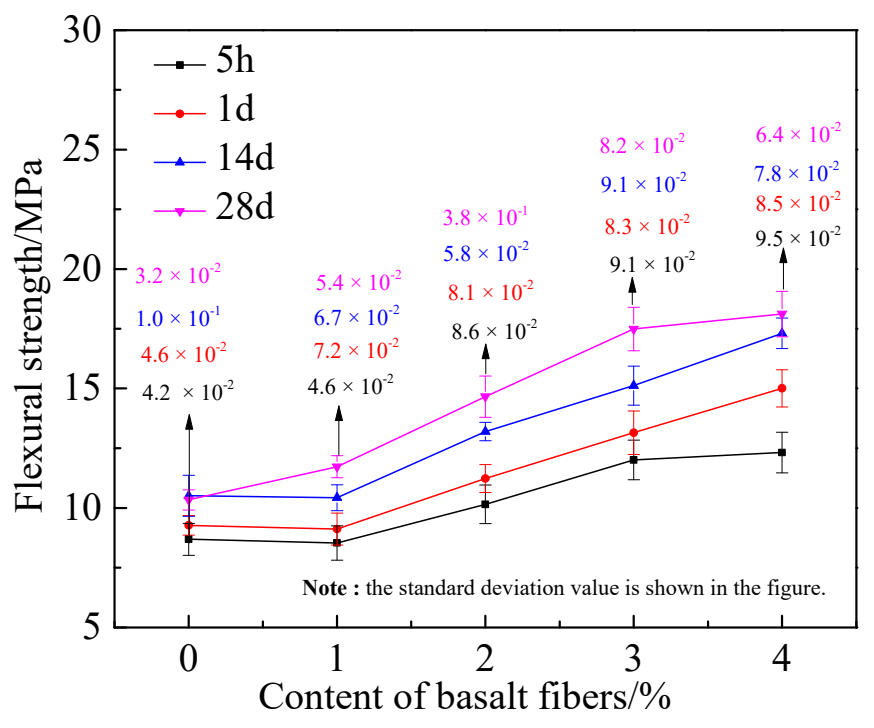

(a) Flexural strength

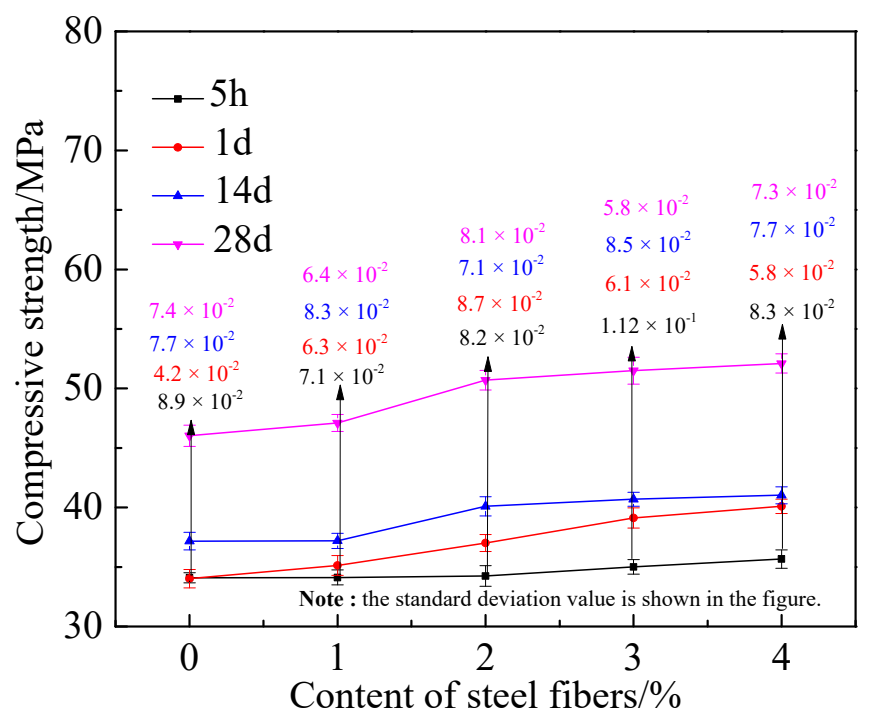

(b) Compressive strength

Figure 3. The mechanical strength of basalt fibers reinforced SAC-RPC.

Figure 4 shows the bonding strength $(\tau)$ of cement mortar repaired by basalt fibers reinforced SAC-RPC. As shown in Figure 4, the curing ages and the dosages of basalt fibers demonstrated positive roles on the bonding strength of basalt fibers reinforced SAC-RPC. It could be observed from Figure 4 that the volume ratio of $3 \%$ was the threshold value of bonding strength. When the dosage of basalt fibers increased from $0 \%$ to $3 \%$, the bonding strength of basalt fibers reinforced SAC-RPC increased sharply with the increasing dosages of basalt fibers. When the content of basalt fibers was higher than 3\%, the bonding strength of basalt fibers reinforced SAC-RPC kept at a stable value.

Figure 5 shows the bonding strength loss rate $(\eta)$ compared to that of flexural strength $\left(f_{t}\right)$ which can be expressed in Equation (1).

$$
\eta=\frac{f_{t}-\tau}{f_{t}}
$$

As shown in Figure 5, the bonding strength loss rate ranged from 52.63\% to 65.73\%, indicating that the bonding strength was $34.27-47.37 \%$ of the flexural strength. It can be observed from Figures 3-5 that the error bars of mechanical strengths are relatively low (less than 0.1), indicating a low discreteness in the experimental observations. Moreover, it could be observed from Figures 3-5, the addition of basalt fibers was more favorable to the flexural and bonding strengths than that of compressive strength. 


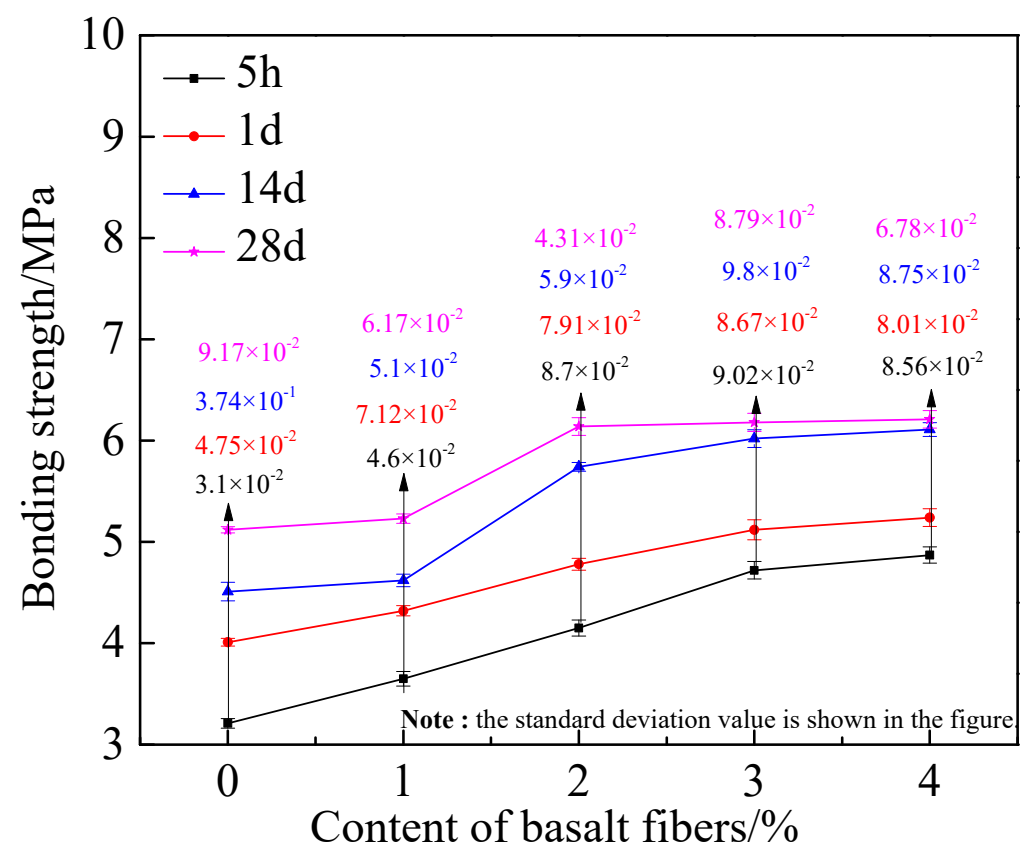

Figure 4. Bonding strength of cement mortar repaired by SAC-RPC.

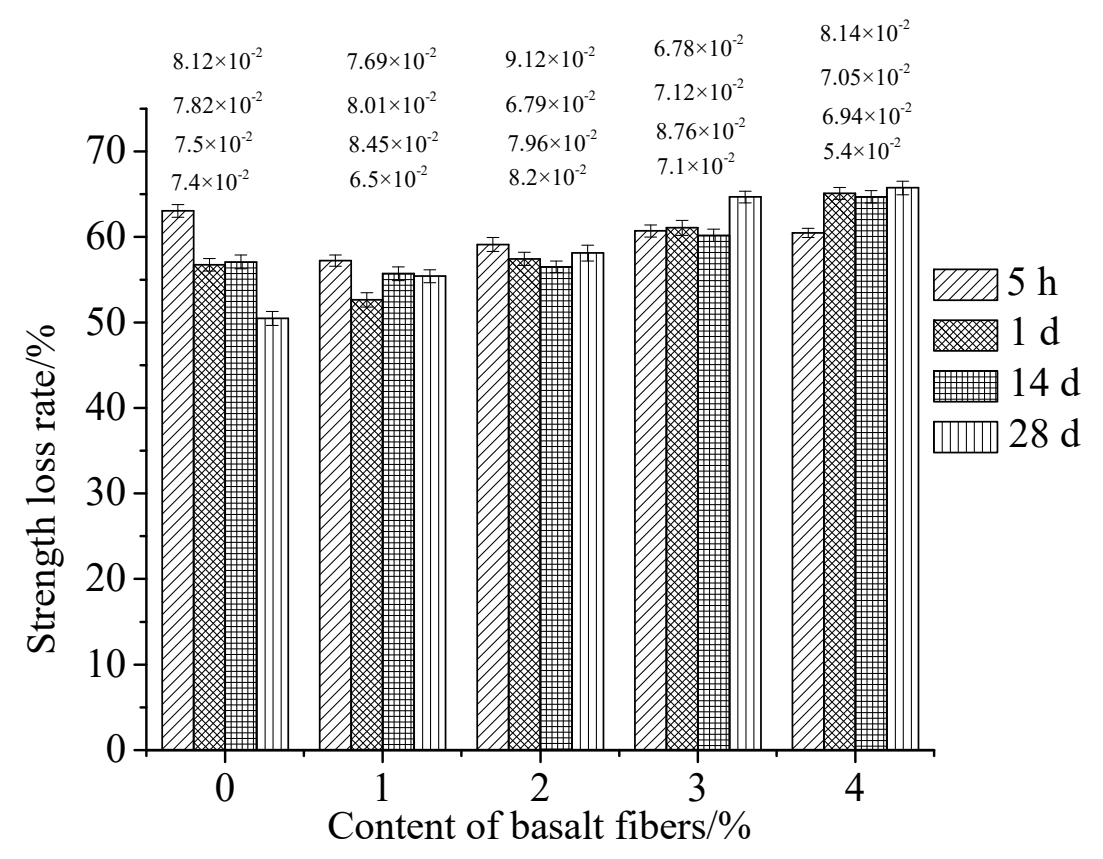

Figure 5. The bonding strength loss rate compared to that of flexural strength.

\subsection{Mechanical Properties of SAC-RPC during NaCl Freeze-Thaw Cycles}

Figure 6 demonstrates the mass loss of basalt fibers reinforced SAC-RPC during $\mathrm{NaCl}$ freeze-thaw cycles. Table 3 shows the fitting results of the relationship between the number of freeze-thaw cycles and mass loss rate. As illustrated in Figure 6 and Table 3, the mass loss rate of the basalt fibers reinforced SAC-RPC increased in the form of quadratic growth function. This was attributed to the fact that the $\mathrm{NaCl}$ freeze-thaw cycles could make the inner frost heaving stress of basalt fibers reinforced SAC-RPC increasing, leading to the mass loss of SAC-RPC increased. [37,38]. Meanwhile, as obtained from Figure 6 that the addition of basalt fibers could effectively decrease the mass loss rate and improve the resistance of $\mathrm{NaCl}$ freeze-thaw cycles. 


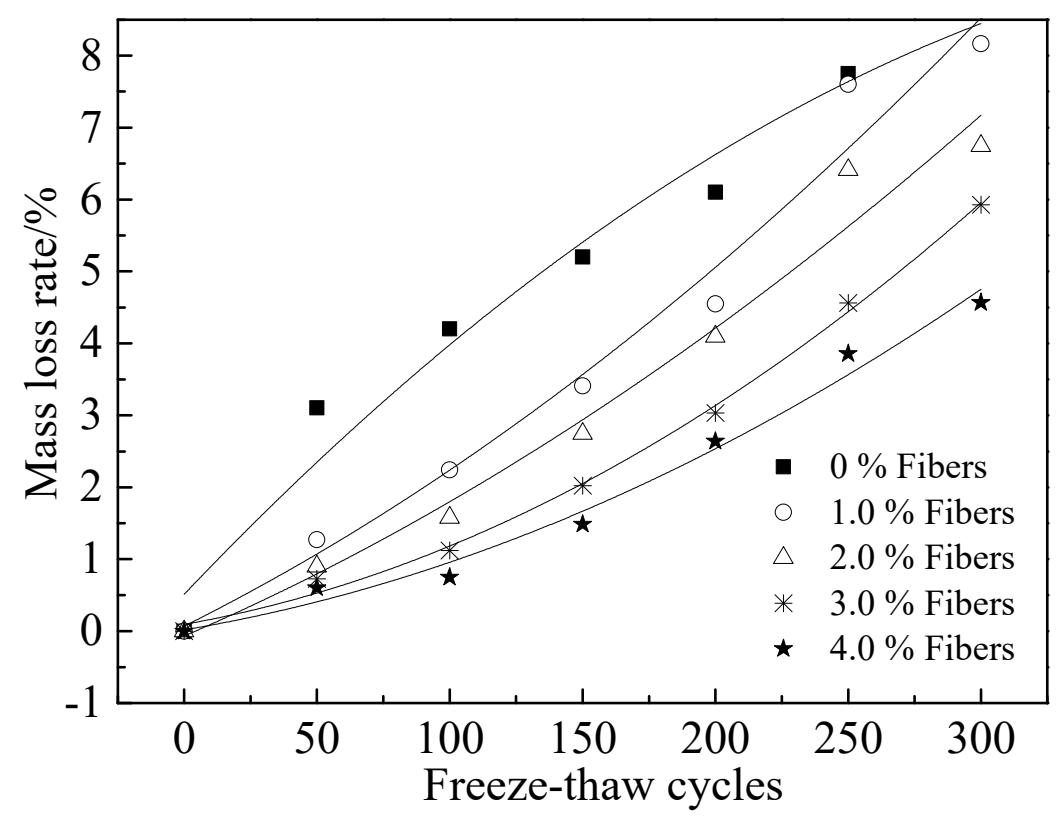

Figure 6. The mass loss rate of SAC-RPC during $\mathrm{NaCl}$ freeze-thaw cycles.

Table 3. The fitting results of mass loss rate and the number of $\mathrm{NaCl}$ freeze-thaw cycles $(N)$.

\begin{tabular}{cccccc}
\hline Equation & $\begin{array}{c}\text { Fibers } \\
\text { Content/\% }\end{array}$ & $\boldsymbol{a}$ & $\boldsymbol{b}$ & $\boldsymbol{c}$ & $\boldsymbol{R}^{\mathbf{2}}$ \\
\hline \multirow{2}{*}{$=a N^{2}+b N+c$} & 0 & 0.03881 & $-4.12 \times 10^{-5}$ & 0.512 & 0.964 \\
& 1 & 0.01845 & $3.25 \times 10^{-5}$ & 0.0689 & 0.967 \\
& 2 & 0.01595 & $2.73 \times 10^{-5}$ & -0.0685 & 0.967 \\
& 3 & 0.00656 & $4.33 \times 10^{-5}$ & 0.0935 & 0.996 \\
\hline
\end{tabular}

Figure 7 presents the mechanical strengths loss rate of basalt fibers reinforced SACRPC during $\mathrm{NaCl}$ freeze-thaw cycles. Table 4 shows the fitting results of mechanical loss rate and the number of $\mathrm{NaCl}$ freeze-thaw cycles $(\mathrm{N})$. As illustrated in Figure 7 and Table 4, the mechanical strengths loss rate of SAC-RPC increased in the form of quadratic function with the number of $\mathrm{NaCl}$ freeze-thaw cycles. This was attributed to the fact that the $\mathrm{NaCl}$ freeze-thaw cycles could increase the inner cracks of basalt fibers reinforced SAC-RPC, meanwhile, the $\mathrm{NaCl}$ freeze-thaw cycles caused the freeze-thaw fatigue to the basalt fibers reinforced SAC-RPC and reduced the mechanical strengths of basalt fibers reinforced SACRPC. Furthermore, the addition of basalt fibers could effectively improve the attenuation of $\mathrm{NaCl}$ freeze-thaw cycles due to the limiting effect of freeze-thaw cracks [39,40]. Moreover, the basalt fibers possess excellent corrosion resistance of corrosion. Consequently, the addition of basalt fibers demonstrated positive effect on the resistance of $\mathrm{NaCl}$ freeze-thaw cycles. It can be obtained from Figure $7 \mathrm{a}-\mathrm{c}$, the compressive strength decreased the least during the $\mathrm{NaCl}$ freeze-thaw cycles, however, the flexural strength lost the highest. 


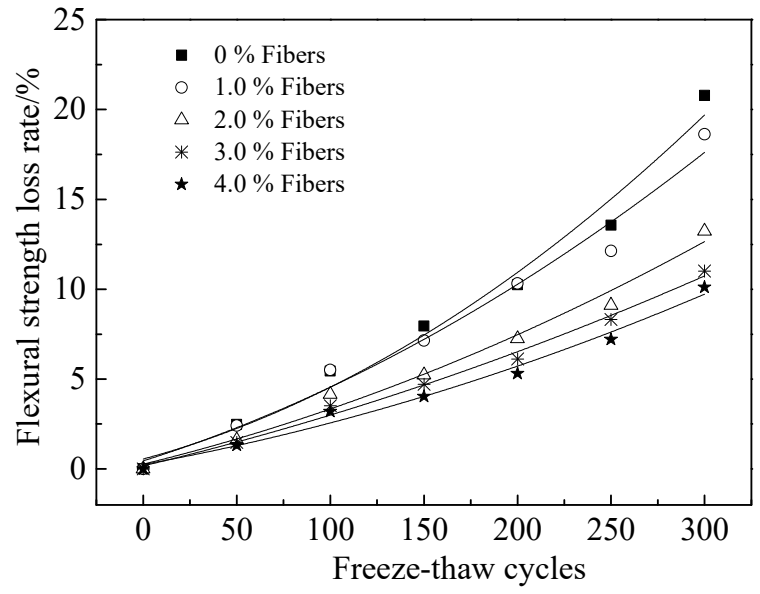

(a)

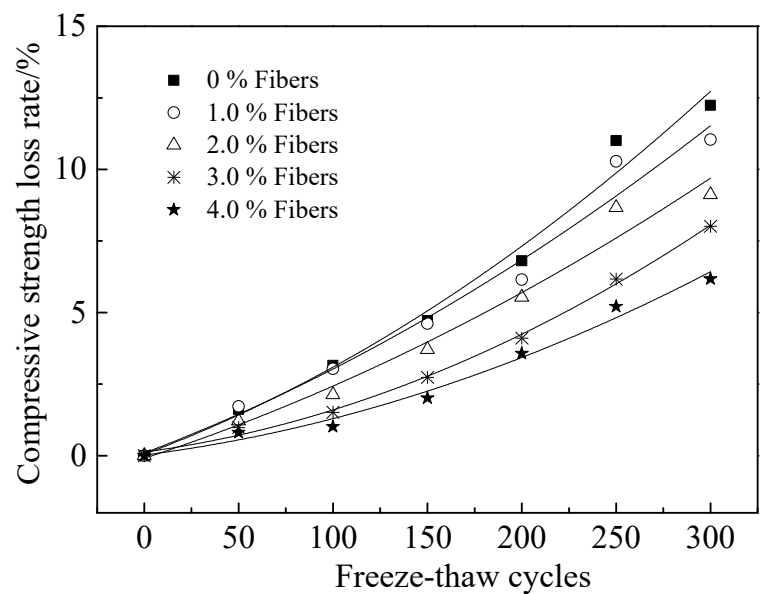

(b)

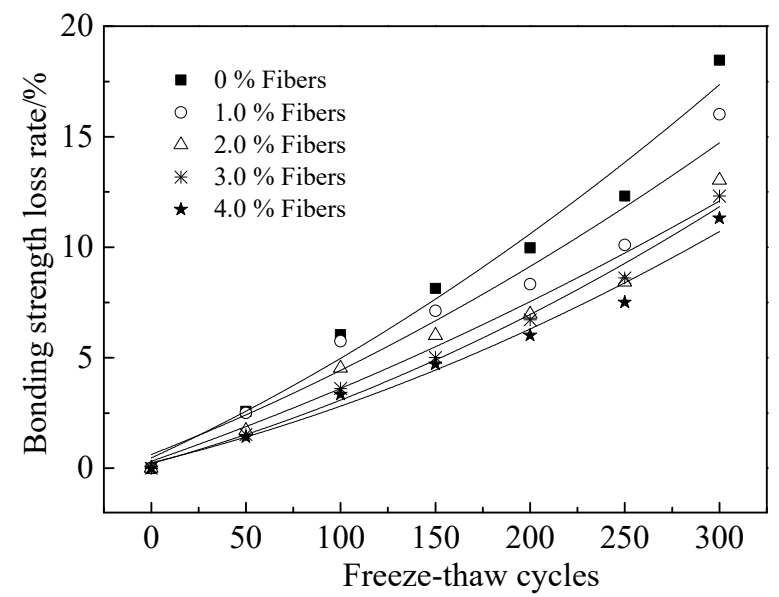

(c)

Figure 7. The mechanical strengths loss rate of SAC-RPC during $\mathrm{NaCl}$ freeze-thaw cycles. (a) The flexural strength loss rate, (b) the compressive strength loss rate, (c) the bonding strength loss rate. 
Table 4. The fitting results of mechanical loss rate and the number of $\mathrm{NaCl}$ freeze-thaw cycles $(N)$.

\begin{tabular}{|c|c|c|c|c|c|c|}
\hline Mechanical Strengths & Equation & Fibers Content $/ \%$ & $a$ & $b$ & $c$ & $R^{2}$ \\
\hline \multirow{6}{*}{ Flexural strength } & \multirow{6}{*}{$\frac{\Delta f_{t}}{f_{t}}=a N^{2}+b N+c$} & 0 & 0.0281 & $1.19 \times 10^{-4}$ & 0.554 & 0.974 \\
\hline & & 1 & 0.0329 & $8.10 \times 10^{-5}$ & 0.449 & 0.970 \\
\hline & & 2 & 0.0255 & $5.28 \times 10^{-5}$ & 0.267 & 0.978 \\
\hline & & 3 & 0.0248 & $3.47 \times 10^{-5}$ & 0.170 & 0.990 \\
\hline & & 4 & 0.0189 & $4.23 \times 10^{-5}$ & 0.247 & 0.980 \\
\hline & & 0 & 0.0245 & $5.92 \times 10^{-5}$ & 0.0519 & 0.977 \\
\hline \multirow{3}{*}{ Compressive strength } & \multirow{4}{*}{$\frac{\Delta f_{c u}}{f_{c u}}=a N^{2}+b N+c$} & 1 & 0.0249 & $4.39 \times 10^{-5}$ & 0.0931 & 0.967 \\
\hline & & 2 & 0.0216 & $3.69 \times 10^{-5}$ & -0.0926 & 0.967 \\
\hline & & 3 & 0.00887 & $5.85 \times 10^{-5}$ & 0.126 & 0.996 \\
\hline \multirow{6}{*}{ Bonding strength } & & 4 & 0.00839 & $4.32 \times 10^{-5}$ & 0.0234 & 0.980 \\
\hline & \multirow{5}{*}{$\frac{\Delta \tau}{\tau}=a N^{2}+b N+c$} & 0 & 0.0395 & $5.60 \times 10^{-5}$ & 0.468 & 0.964 \\
\hline & & 1 & 0.0336 & $4.46 \times 10^{-5}$ & 0.622 & 0.930 \\
\hline & & 2 & 0.0298 & $3.14 \times 10^{-5}$ & 0.317 & 0.944 \\
\hline & & 3 & 0.0237 & $5.02 \times 10^{-5}$ & 0.215 & 0.985 \\
\hline & & 4 & 0.0211 & $4.61 \times 10^{-5}$ & 0.247 & 0.972 \\
\hline
\end{tabular}

3.3. Mechanical Properties of SAC-RPC during the Coupling Effect of Carbonation and $\mathrm{NaCl}$ Freeze-Thaw Cycles

The carbonation depth of basalt fibers reinforced SAC-RPC is shown in Figure 8. Table 5 shows the results of the fitting parameters. As depicted in Figure 8 and Table 5, the carbonation depth of basalt fibers reinforced SAC-RPC demonstrated a descending trend with the volume of basalt fibers. The fitting equation of the relationship between the volume of basalt fibers and carbonation depth conforms to the quadratic decreasing function. Meanwhile, the $\mathrm{NaCl}$ freeze-thaw cycles could lead to increasing the carbonation depth. This was attributed to the fact that the basalt fibers could decrease the number and size of cracks in SAC-RPC thus decreasing the contact of $\mathrm{CO}_{2}$ and $\mathrm{Ca}(\mathrm{OH})_{2}$ leading eventually to decreasing the carbonation depth of basalt fibers reinforced SAC-RPC [41,42]. However, the $\mathrm{NaCl}$ freeze-thaw cycles were able to accelerate the formation and propagation of cracks thus increasing the carbonation depth of basalt fibers reinforced SAC-RPC.

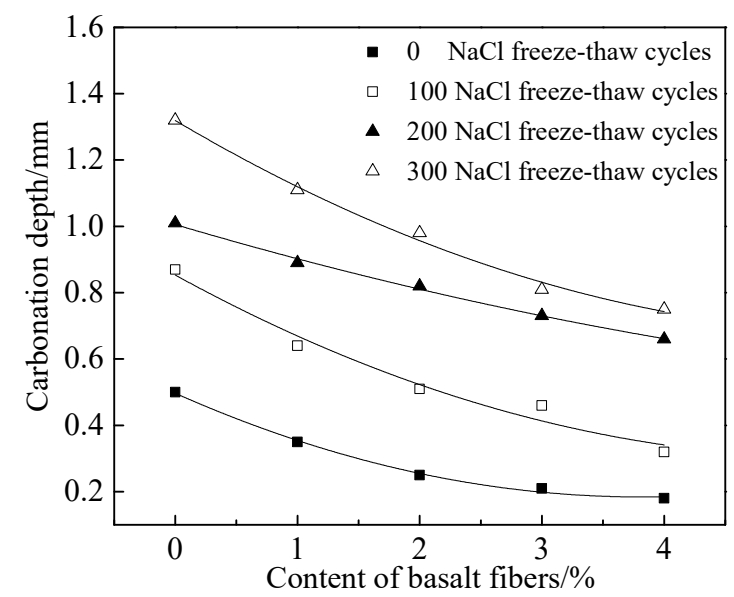

Figure 8. Carbonation depth of SAC-RPC during different $\mathrm{NaCl}$ freeze-thaw cycles. 
Table 5. The fitting results of basalt fibers volume and the carbonation depth.

\begin{tabular}{cccccc}
\hline Equation & NaCl Freeze-Thaw Cycles & $\boldsymbol{a}$ & $\boldsymbol{b}$ & $\boldsymbol{c}$ & $\boldsymbol{R}^{\mathbf{2}}$ \\
\hline & 0 & -0.164 & 0.0214 & 0.497 & 0.994 \\
$D=a V^{2}+b V+c$ & 100 & -0.202 & 0.0186 & 0.853 & 0.954 \\
& 200 & -0.109 & 0.00571 & 1.005 & 0.993 \\
& 300 & -0.218 & 0.0186 & 1.319 & 0.989 \\
\hline
\end{tabular}

Figure 9 shows the mechanical strengths loss rate of SAC-RPC under the coupling effect of carbonation and $\mathrm{NaCl}$ freeze-thaw cycles. Table 6 is the fitting result of mechanical loss rate and the volume of basalt fibers. It can be observed from Figure 9 and Table 6, the mechanical strengths loss rate decreased in the form of the quadratic function with the increasing dosage of basalt fibers. This was attributed to the limiting effect of basalt fibers on cracks [43]. When only carbonation was applied to the SAC-RPC the mechanical strengths rarely changed due to the fact that the substances $\left(\mathrm{CaCO}_{3}\right)$ produced by carbonation reaction demonstrated little influence on the mechanical strengths of SAC-RPC. However, when the coupling effect of carbonation and $\mathrm{NaCl}$ freeze-thaw cycles acted on the SACRPC, the mechanical strengths loss rate increased obviously with the increasing numbers of $\mathrm{NaCl}$ freeze-thaw cycles. The $\mathrm{NaCl}$ freeze-thaw cycles could accelerate the development of internal cracks which in turn facilitate the ingression of carbon dioxide to corrode the cement matrix. These two factors will be coupled and further accelerate the deterioration of SAC-RPC. As obtained from Figure 9a-c, the flexural strength of SAC-RPC decayed the most seriously under the environment of coupling effect of salt freeze-thaw cycles and carbonation. However, the attenuation of the compressive strength was the least.

Table 6. The fitting results of mechanical loss rate and the volume of basalt fibers $(V)$ under the coupling effect of carbonation and $\mathrm{NaCl}$ freeze-thaw cycles.

\begin{tabular}{|c|c|c|c|c|c|c|}
\hline Mechanical Strengths & Equation & $\mathrm{NaCl}$ Freeze-Thaw Cycles & $a$ & $b$ & $c$ & $R^{2}$ \\
\hline \multirow{5}{*}{ Flexural strength } & \multirow{5}{*}{$\frac{\Delta f_{t}}{f_{t}}=a V^{2}+b V+c$} & 0 & -0.344 & 0.0874 & -0.338 & 0.860 \\
\hline & & 100 & -1.523 & 0.0871 & 8.777 & 0.989 \\
\hline & & 200 & -2.773 & 0.127 & 16.129 & 0.999 \\
\hline & & 300 & -5.586 & 0.543 & 22.807 & 0.985 \\
\hline & & 0 & -0.297 & 0.0511 & 0.486 & 0.741 \\
\hline \multirow{4}{*}{ Compressive strength } & \multirow{4}{*}{$\frac{\Delta f_{c u}}{f_{c u}}=a V^{2}+b V+c$} & 100 & -1.342 & 0.129 & 6.412 & 0.974 \\
\hline & & 200 & -1.699 & 0.114 & 11.127 & 0.937 \\
\hline & & 300 & -2.304 & 0.0893 & 17.477 & 0.940 \\
\hline & & 0 & -0.240 & 0.0232 & 0.722 & 0.987 \\
\hline \multirow[t]{3}{*}{ Bonding strength } & \multirow{3}{*}{$\frac{\Delta \tau}{\tau}=a V^{2}+b V+c$} & 100 & -1.342 & 0.129 & 6.412 & 0.974 \\
\hline & & 200 & -3.242 & 0.400 & 12.898 & 0.888 \\
\hline & & 300 & -2.31571 & 0.0614 & 20.227 & 0.989 \\
\hline
\end{tabular}

It can be obtained from this study that the addition of basalt fibers showed better enhancement effect on the flexural and bonding strengths of SAC-RPC. However, the flexural and bonding strengths descended more obviously than that of the compressive strength. Compared the basalt fibers with the steel fibers reinforced SAC-RPC [24], basalt fibers reinforced SAC-RPC showed more excellent resistance to the $\mathrm{NaCl}$ freeze-thaw cycles. Furthermore, the mechanical strengths of basalt fibers reinforced SAC-RPC was worse than that of steel fibers reinforced SAC-RPC. 


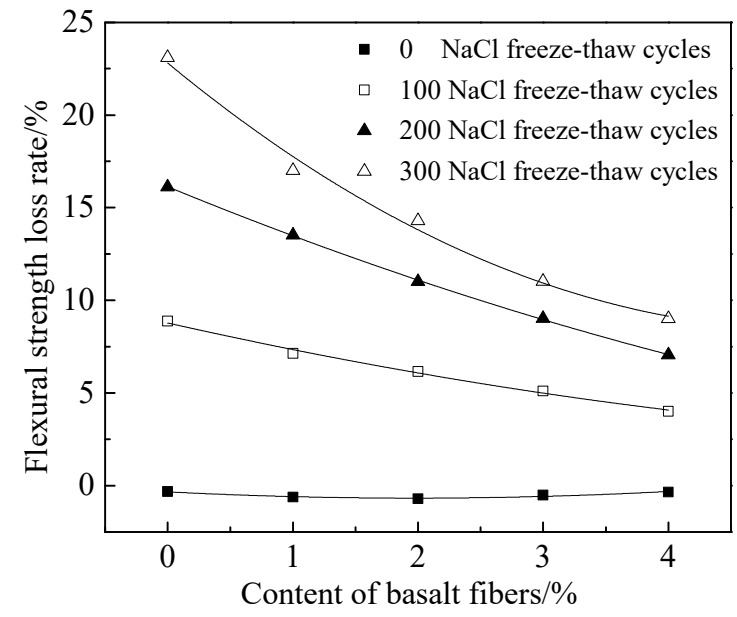

(a)

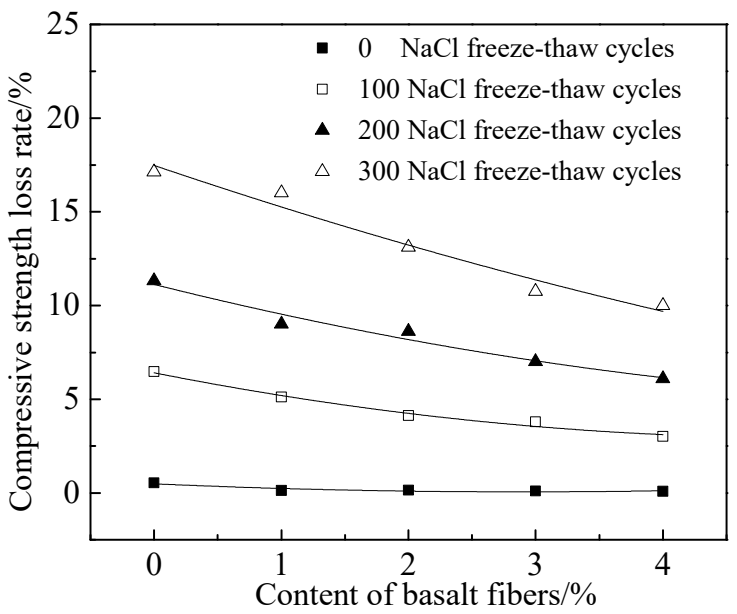

(b)

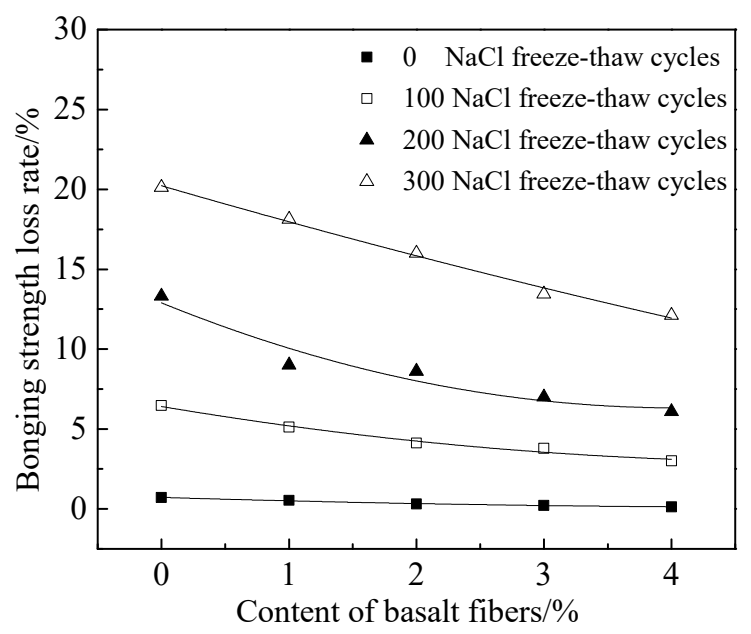

(c)

Figure 9. The mechanical strengths loss rate of SAC-RPC under the coupling effect of carbonation and $\mathrm{NaCl}$ freeze-thaw cycles, (a) The flexural strength loss rate, (b) The compressive strength loss rate, (c) The bonding strength loss rate.

\section{Conclusions}

In this study, the mechanical strengths of basalt fibers reinforced SAC-RPC and the bonding strength of cement mortar repaired by this material were investigated. Moreover, 
the following resistance to $\mathrm{NaCl}$ freeze-thaw cycles and the coupling effect of $\mathrm{NaCl}$ freezethaw cycles and carbonation were researched. The conclusions were summarized as follows:

1. The addition of basalt fibers demonstrated positive effect on the mechanical strengths and the resistance of $\mathrm{NaCl}$ freeze-thaw cycles and carbonation. The basalt fibers' volume of $3 \%$ was the threshold value of the mechanical strengths. The enhancing effect of basalt fibers on flexural and bonding strengths was more obvious than that of compressive strength. When the curing age was higher or equal to $5 \mathrm{~h}$, the flexural, compressive and bonding strengths of SAC-RPC were higher than $8.53 \mathrm{MPa}, 34 \mathrm{MPa}$ and 3.21 MPa, respectively.

2. The mass loss and the mechanical strengths of basalt fibers reinforced SAC-RPC showed an increasing quadratic function with the increasing number of $\mathrm{NaCl}$ freezethaw cycles. Meanwhile, the loss rate of mechanical strengths and carbonation depth decreased in the form of quadratic function with the volume of basalt fibers.

3. The carbonation demonstrated little effect on the mechanical strengths of basalt fibers reinforced SAC-RPC. However, the coupling effect of carbonation and $\mathrm{NaCl}$ freezethaw cycles could accelerate the attenuation of mechanical properties. The SAC-RPC with basalt fibers showed better resistance to $\mathrm{NaCl}$ freeze-thaw cycles than that of steel fibers reinforced SAC-RPC. Furthermore, the mechanical strengths of SAC-RPC with basalt fibers were worse.

Author Contributions: Conceptualization, H.W. and G.H.; methodology, G.H.; software, F.S.; validation, H.W., G.H. and F.S.; formal analysis, H.W.; investigation, G.H.; resources, H.W.; data curation, F.S.; writing—original draft preparation, G.H.; writing—review and editing, H.W.; visualization, G.H.; supervision, H.W.; project administration, G.H.; funding acquisition, H.W. All authors have read and agreed to the published version of the manuscript.

Funding: This work is sponsored by National Natural Science Foundation of China [No. 51808300].

Institutional Review Board Statement: Not applicable.

Informed Consent Statement: Not applicable.

Data Availability Statement: The data used to support the findings of this study are available from the corresponding author upon request.

Conflicts of Interest: The authors declare that there are no conflicts of interest regarding the publication of this paper.

\section{References}

1. Li, Y.; Li, X.; Tan, Y. Effect of aging on fatigue performance of cement emulsified asphalt repair material. Constr. Build. Mater. 2021, 292, 123417. [CrossRef]

2. Wei, Y.; Gao, X.; Zhang, Q. Evaluating performance of concrete pavement joint repair using different materials to reduce reflective cracking in asphalt concrete overlay. Road Mater. Pavement Des. 2014, 15, 966-976. [CrossRef]

3. Qiao, F.; Chau, C.; Li, Z. Property evaluation of magnesium phosphate cement mortar as patch repair material. Constr. Build. Mater. 2010, 24, 695-700. [CrossRef]

4. Wang, Y.; Ye, J.; Liu, Y.; Qiang, X.; Feng, L. Influence of freeze-thaw cycles on properties of asphalt-modified epoxy repair materials. Constr. Build. Mater. 2013, 41, 580-585. [CrossRef]

5. Ahmad, M.; Chen, B.; Haque, M. Multiproperty characterization of cleaner and energy-efficient vegetal concrete based on one-part geopolymer binder. J. Clean. Prod. 2020, 253, 119916. [CrossRef]

6. Mestres, G.; Aguilera, F.S.; Manzanares, N.; Sauro, S.; Osorio, R.; Toledano, M.; Ginebra, M.P. Magnesium phosphate cements for endodontic applications with improved long-term sealing ability. Int. Endod. J. 2014, 47, 127-139. [CrossRef]

7. Mo, Z.; Gao, X.; Su, A. Mechanical performances and microstructures of metakaolin contained UHPC matrix under steam curing conditions. Constr. Build. Mater. 2021, 268, 121112. [CrossRef]

8. Cai, G.; Zhao, J. Application of sulphoaluminate cement to repair deteriorated concrete members in chloride ion rich environmentA basic experimental investigation of durability properties. KSCE J. Civil Eng. 2016, 20, 2832-2841. [CrossRef]

9. Xu, L.; Liu, S.; Li, N.; Peng, Y.; Wu, K.; Wang, P. Retardation effect of elevated temperature on the setting of calcium sulfoaluminate cement clinker. Constr. Build. Mater. 2018, 178, 112-119. [CrossRef] 
10. Jin, B.; Chen, L.; Chen, B. Factors assessment of a repair material for brick masonry loaded cracks using magnesium phosphate cement. Constr. Build. Mater. 2020, 252, 119098. [CrossRef]

11. Ostrowski, N.; Roy, A.; Kumta, P.N. Magnesium phosphate cement systems for hard tissue applications: A review. ACS Biomater. Sci. Eng. 2016, 2, 1067-1083. [CrossRef] [PubMed]

12. Yang, Q.; Wu, X. Factors influencing properties of phosphate cement based binder for rapid repair of concrete. Cem. Concr. Res. 1999, 29, 389-396. [CrossRef]

13. Velazco, G.; Almanza, J.M.; Cortés, D.A.; Escobedo, J.C.; Escalante-García, J.I. Effect of citric acid and the hemihydrate amount on the properties of a calcium sulphoaluminate cement. Mater. Constr. 2014, 64, 1-8. [CrossRef]

14. Liu, Y.; Tian, W.; Wang, M.; Qi, B.; Wang, W. Rapid strength formation of on-site carbon fiber reinforced high-performance concrete cured by ohmic heating. Constr. Build. Mater. 2020, 244, 118344. [CrossRef]

15. Feng, H.; Chen, G.; Hadi, M.N.; Sheikh, M.N.; Zhou, B. Mechanical behaviour of micro-fine steel fibre reinforced sulphoaluminate cement composite. Constr. Build. Mater. 2018, 170, 91-100. [CrossRef]

16. Mohd, S.; Jagdish, P.; Amjad, M. Effect of GGBFS on time dependent compressive strength of concrete. Constr. Build. Mater. 2010, 24, 1469-1478.

17. Sajedi, F.; Razak, H. Effects of curing regimes and cement fineness on the compressive strength of ordinary Portland cement mortars. Constr. Build. Mater. 2011, 25, 2036-2045. [CrossRef]

18. Singh, M.; Kapur, P.C. Preparation of calcium sulphoaluminate cement using fertiliser plant wastes. J. Hazard. Mater. 2008, 157, 106-113. [CrossRef]

19. Ma, B.; Li, H.; Mei, J.; Li, X. Influence of nano-SiO 2 addition on properties of sulphoaluminate cement based material. J. Wuhan Univ. Technol. Mater. Sci. Ed. 2017, 32, 106-112. [CrossRef]

20. Zhang, J.; Chen, T.; Gao, X. Incorporation of self-ignited coal gangue in steam cured precast concrete. J. Clean. Prod. 2021, 292, 126004. [CrossRef]

21. Liu, Q.-F.; Iqbal, M.F.; Yang, J.; Lu, X.-Y.; Zhang, P.; Rauf, M. Prediction of chloride diffusivity in concrete using artificial neural network: Modelling and performance evaluation. Constr. Build. Mater. 2021, 266, 121082. [CrossRef]

22. Ren, M.; Wen, X.; Gao, X.; Liu, Y. Thermal and mechanical properties of ultra-high performance concrete incorporated with microencapsulated phase change material. Constr. Build. Mater. 2021, 273, 121714. [CrossRef]

23. Huang, H.; Gao, X.; Khayat, K. Contribution of fiber orientation to enhancing dynamic properties of UHPC under impact loading. Cem. Concr. Compos. 2021, 121, 104108. [CrossRef]

24. Hong, X.; Wang, H.; Shi, F. Influence of $\mathrm{NaCl}$ freeze thaw cycles and cyclic loading on the mechanical performance and permeability of sulphoaluminate cement reactive powder concrete. Coatings 2020, 10, 1227. [CrossRef]

25. James, A.; Bazarchi, E.; Chiniforush, A.A.; Aghdam, P.P.; Hosseini, M.R.; Akbarnezhad, A.; Martek, I.; Ghodoosi, F. Rebar corrosion detection, protection, and rehabilitation of reinforced concrete structures in coastal environments: A review. Constr. Build. Mater. 2019, 224, 1026-1039. [CrossRef]

26. Pelletier-Chaignat, L.; Winnefeld, F.; Lothenbach, B.; Müller, C.J. Beneficial use of limestone filler with calcium sulphoaluminate cement. Constr. Build. Mater. 2012, 26, 619-627. [CrossRef]

27. Zhou, Y.; Xu, C.; Wang, X.; Dou, Y.; Huan, Z.; Chang, J. Fast setting tricalcium silicate/magnesium phosphate premixed cement for root canal filling. Ceram. Int. 2014, 47, 127-139. [CrossRef]

28. Haque, M.; Chen, B. Research progresses on magnesium phosphate cement: A review. Constr. Build. Mater. 2019, 211, 885-898. [CrossRef]

29. Oderji, S.Y.; Chen, B.; Ahmad, M.R.; Shah, S.F.A. Fresh and hardened properties of one-part fly ash-based geopolymer binders cured at room temperature: Effect of slag and alkali activators. J. Clean. Prod. 2019, 225, 1-10. [CrossRef]

30. Gao, L.; Adesina, A.; Das, S. Properties of eco-friendly basalt fibre reinforced concrete designed by Taguchi method. Constr. Build. Mater. 2021, 302, 124161. [CrossRef]

31. The State Bureau of Quality and Technical Supervision. Method of Testing Cements-Determination of Strength; GB/T 17671-1999; The State Bureau of Quality and Technical Supervision: Beijing, China, 1999.

32. Ministry of housing and urban rural development of the people's Republic of China. Standard for Test Method of Long-Term Performance and Durability of Ordinary Concrete; GB/T 50082-2009; Ministry of Housing and Urban Rural Development of the People's Republic of China: Beijing, China, 2009.

33. Branston, J.; Das, S.; Kenno, S.; Taylor, C. Mechanical behaviour of basalt fibre reinforced concrete. Constr. Build. Mater. 2016, 124, 878-886. [CrossRef]

34. Wei, B.; Cao, H.; Song, S. Tensile behavior contrast of basalt and glass fibers after chemical treatment. Mater. Des. 2010, 31, 4244-4250. [CrossRef]

35. Haido, J. Flexural behavior of basalt fiber reinforced concrete beams: Finite element simulation with new constitutive relationships Structures 2020, 27, 1876-1889. [CrossRef]

36. Katkhuda, H.; Shatarat, N. Improving the mechanical properties of recycled concrete aggregate using chopped basalt fibers and acid treatment. Constr. Build. Mater. 2017, 140, 328-335. [CrossRef]

37. Wang, H.; Gao, X.; Liu, J. Effects of salt freeze-thaw cycles and cyclic loading on the piezoresistive properties of carbon nanofibers mortar. Constr. Build. Mater. 2018, 177, 192-201. [CrossRef] 
38. Wang, H.; Jin, K.; Zhang, A.; Han, Y.; Liu, J. External erosion of sodium chloride on the degradation of self-sensing and mechanical properties of aligned stainless steel fiber reinforced reactive powder concrete. Constr. Build. Mater. 2021, $275,06629$.

39. Niu, D.; Su, L.; Luo, Y.; Huang, D.; Luo, D. Experimental study on mechanical properties and durability of basalt fiber reinforced coral aggregate concrete. Constr. Build. Mater. 2020, 237, 117628. [CrossRef]

40. Borhan, T. Properties of glass concrete reinforced with short basalt fibre. Mater. Des. 2012, 42, 265-271. [CrossRef]

41. Qin, L.; Gao, X.; Su, A.; Li, Q. Effect of carbonation curing on sulfate resistance of cement-coal gangue paste. J. Clean. Prod. 2021, 278, 123897. [CrossRef]

42. Lei, L.; Wang, Q.; Xu, S.; Wang, N.; Zheng, X. Fabrication of superhydrophobic concrete used in marine environment with anti-corrosion and stable mechanical properties. Constr. Build. Mater. 2020, 251, 118946. [CrossRef]

43. Li, J.; Yang, S.; Liu, Y.; Muhammad, Y.; Su, Z.; Yang, J. Studies on the properties of modified heavy calcium carbonate and SBS composite modified asphalt. Constr. Build. Mater. 2019, 218, 413-423. [CrossRef] 